\title{
Evaluation of an Ultra-Short MRI Protocol for Cerebral Staging Examinations in Melanoma Patients
}

\section{Evaluation eines ultrakurzen MRT-Protokolls zum zerebralen Staging bei Melanom-Patienten}

Authors

Sönke Peters $^{1}{ }^{\mathbb{D}}$, Friederike Gärtner ${ }^{1}$, Friederike Austein ${ }^{2}$, Fritz Wodarg ${ }^{1}$, Olav Jansen ${ }^{1}$, Johannes Hensler ${ }^{10}$

Affiliations

1 Department of Radiology and Neuroradiology, Universitätsklinikum Schleswig-Holstein Campus Kiel, Germany

2 Department of Diagnostic and Interventional Neuroradiology, Universitätsklinikum HamburgEppendorf, Hamburg, Germany

Key words

MR imaging, melanoma, metastases, CNS, brain neoplasms, brain, radiologists, staging

received 29.06.2021

accepted 03.10.2021

published online 18.11.2021

Bibliography

Fortschr Röntgenstr 2022; 194: 409-415

DOI 10.1055/a-1669-9408

ISSN 1438-9029

(C) 2021. Thieme. All rights reserved.

Georg Thieme Verlag KG, Rüdigerstraße 14,

70469 Stuttgart, Germany

Correspondence

Dr. Sönke Peters

Universitätsklinikum Schleswig-Holstein, Campus Kiel,

Klinik für Radiologie und Neuroradiologie,

Arnold-Heller-Str. 3, 24105 Kiel, Germany

Tel.: $+49 / 431 / 5974806$

soenke.peters@uksh.de

\section{ABSTRACT}

Purpose Due to its high sensitivity and lack of radiation, MRI is often used to stage cerebral tumors in patients. In contrast, the relatively long examination times and the limited availability of MRI slots at the clinic might delay these examinations. The aim of this study was to compare an ultra-short MRI protocol with the routinely used standard protocol.

Materials and Methods Cerebral MRI of 147 patients with malignant melanoma were evaluated retrospectively, whereby only two sequences (FLAIR images and contrast-enhanced T1 MPR images) were evaluated in one group and images from the whole examination were available for the second group, including five sequences (DWI, T2 TSE, FLAIR, native and contrast-enhanced T1 TSE, and contrast-enhanced T1
MPR). The results of the two groups were compared and tested to determine whether the ultra-short approach was inferior to the full examination.

Results $13.6 \%$ of the patients had cerebral metastases. Overall, 73 metastases were detected: 60 were located supratentorially and 13 infratentorially. Concerning the detection of cerebral metastases, the ultra-short MRI examination, involving only a FLAIR and a contrast-enhanced T1 MPR sequence, was not inferior to the full MRI protocol in general $(p=0.017)$ and separated by location for supratentorial $(p=0.026)$ and infratentorial $(p=0.001)$ metastases.

Conclusion For staging purposes, a focused, ultra-short MRI protocol is not inferior to a standard MRI examination. This might open up opportunities for faster staging processes and a more efficient use of the often-restricted MRI capacities.

\section{Key Points}

- Short MRI protocols for cerebral staging are not inferior to standard examinations.

- Contrast-enhanced images represent the centerpiece of an ultra-short MRI protocol.

- Short MRI protocols might enable a more efficient use of restricted resources.

\section{Citation Format}

- Peters S, Gärtner F, Austein F et al. Evaluation of an UltraShort MRI Protocol for Cerebral Staging Examinations in Melanoma Patients. Fortschr Röntgenstr 2022; 194: 409415

\section{ZUSAMMENFASSUNG}

Ziel Aufgrund der hohen Sensitivität ist das MRT die erste Wahl für Staginguntersuchungen des Gehirns bei Tumorpatienten. Die Untersuchungen dauern jedoch relativ lange, was zu einer Limitation der Kapazitäten beiträgt und so den Stagingprozess verzögern kann. Ziel dieser Studie ist es, ein ultrakurzes MRT-Protokoll mit einem ausführlichen RoutineProtokoll zu vergleichen.

Material und Methoden Es wurden 147 zerebrale MRT von Melanom-Patienten ausgewertet. Von einer Gruppe wurden nur 2 Sequenzen bezüglich zerebraler Metastasen beurteilt (Flair und kontrastverstärkte T1 MPR). Die andere Gruppe hatte die gesamte MRT-Untersuchung mit 5 Sequenzen (DWI, T2 TSE, Flair, native und kontrastverstärkte T1 TSE, kontrastverstärkte T1 MPR) zur Verfügung. Die Ergebnisse beider 
Gruppen wurden bezüglich einer Nichtunterlegenheit des ultrakurzen Protokolls statistisch getestet.

Ergebnisse $13.6 \%$ der Melanom-Patienten hatten insgesamt 73 zerebrale Metastasen. Hiervon waren 60 Metastasen supratentoriell und 13 Metastasen infratentoriell gelegen. Das ultrakurze MRT-Protokoll, bestehend aus einer Flair und einer kontrastverstärkten T1 MPR, war dem ausführlichen Protokoll bezüglich der Metastasendetektion generell $(p=0,017)$ sowie für die Lokalisationen supratentoriell $(p=0,026)$ und infratentoriell $(p=0,001)$ statistisch nicht unterlegen.

Schlussfolgerung Zum zerebralen Staging ist ein fokussiertes, ultrakurzes MRT-Protokoll einem ausführlichen Rou-
tine-Protokoll nicht unterlegen. Fokussierte und kurze MRTProtokolle könnten somit einen effizienten Einsatz der oftmals eingeschränkten MRT-Kapazitäten und einen schnellen Stagingprozess ermöglichen.

\section{Kernaussagen:}

- Zum zerebralen Staging ist ein kurzes MRT-Protokoll einem Routineprotokoll nicht unterlegen

- Kontrastmittelverstärkte Aufnahmen sind das Kernstück eines ultrakurzen Staging-Protokolls

- Kurze MRT-Protokolle könnten bei einem effizienteren Einsatz der häufig limitierten MRT-Kapazitäten helfen

\section{Introduction}

MRI represents an excellent method for examining the central nervous system and any underlying pathological conditions. Owing to the high contrast and different imaging aspects, the sensitivity of MRI is high in detecting even small cerebral mass lesions, especially when a gadolinium-based contrast agent is used. Therefore, MRI is the gold standard for cerebral examinations to detect or exclude cerebral metastases [1-3]. Consequently, many guidelines for different tumors call for a cerebral MRI for complete staging, at least at some point to determine the severity of disease [4-6].

Due to the relatively time-consuming examination and the limited scheduling of MRI examinations, a staging examination and any resulting therapy might be delayed in the daily routine. However, the sensitivity of CT examinations, which are widely and rapidly available and often used for thoracoabdominal staging, is significantly lower for intracranial mass lesions. Therefore, CT does not represent a reasonable alternative [7]. To examine more patients per time period and therefore alleviate this situation, shorter examinations are desirable. Faster MRI sequences might offer one option to save time. Some means of speeding up an MRI sequence, such as increased slice thickness or special read-out techniques, often lead to a loss of imaging quality and therefore a loss of sensitivity [8]. However, some newer techniques, for example, parallel imaging, can save time without losing imaging information $[9,10]$. Therefore, this strategy could contribute to reaching the goal of faster MRI examinations. Applying shortened MRI protocols represents another amendatory approach. This approach has already been tested for different regions of the body and to address different questions [11-14]. In both cases it must be ensured that the quality of the examination is sufficient and the sensitivity reliable.

The aim of this study was to evaluate an ultra-short MRI protocol containing just two sequences and compare it with the routinely used standard protocol with six sequences for cerebral staging examinations in patients with malignant melanoma.

\section{Materials and Methods}

The study was approved by the institutional ethics board. We retrospectively screened the archive of our institution for 150 cerebral MRI staging examinations in patients with malignant melanoma.
All examinations were performed on the same 1.5-T MRI scanner (Avanto, Siemens HealthCare) and included axial diffusion-weighted imaging (DWI) (TE = 73 ms; TR=4700 ms; b = 1000 ms; slice thickness $3 \mathrm{~mm}$ ), axial T2 TSE (TE = $94 \mathrm{~ms}$; TR = $9770 \mathrm{~ms}$; slice thickness $3 \mathrm{~mm}$ ), a sagittal fluid-attenuated inversion recovery sequence (FLAIR) (TE = $92 \mathrm{~ms} ; \mathrm{TR}=9000$; slice thickness $5 \mathrm{~mm}$ ), native and a contrast-enhanced axial T1 TSE (TE = $9.6 \mathrm{~ms}$; TR = 498 ms; slice thickness $3 \mathrm{~mm}$ ), and sagittal contrast-enhanced T1 MPR (TE= $3.94 \mathrm{~ms}$; TR = 2040 ms; slice thickness 1 mm). The contrast agent Gadobutrol (Gadovist $1.0 \mathrm{mmol} / \mathrm{ml}$, Bayer HealthCare) was used. It was adapted to the body weight of each patient $(0.1 \mathrm{ml} / \mathrm{kg} \mathrm{BW})$ and injected intravenously before the FLAIR sequence.

Two radiologists with neuroradiologic experience of 7 and 8 years, respectively, and who were blinded to the other sequences or the diagnosis/tumor stage of the patient evaluated the FLAIR sequence and the contrast-enhanced T1 MPR with the software routinely used at our institution (IMPAX, Agfa HealthCare). First, each rater evaluated the imaging quality of both sequences on a scale of $1-5$. Here, 1 represented very poor imaging quality, 2 poor imaging quality, 3 moderate imaging quality, 4 good imaging quality, and 5 excellent imaging quality. Secondly, each rater determined the number of metastases ( $n$ ) according to supratentorial und infratentorial location. In addition, each rater evaluated the images for relevant secondary findings. In cases of divergent results of numbers of metastases, an additional consensus result of the two readers was determined by reevaluating the two sequences together.

In addition, two radiologists with 6 and 9 years of neuroradiologic experience evaluated the whole MRI examination. They were blinded to the diagnosis/tumor stage of the patient in the same manner as described above to determine the number of supratentorial and infratentorial metastases. In cases of divergent results, again, a consensus result of the two readers was reached by reevaluating the sequences together.

Furthermore, the official radiological report was analyzed concerning the number and location of metastases. Finally, the examinations with incongruent results of the full MRI examination, the shortened protocol, or the number of metastases mentioned in the official radiological report were inspected and analyzed. 
- Table 1 Disease severity of the examined melanoma patients shown by the distribution of frequencies of the American Joint Committee on Cancer (AJCC) stage and the TNM scoring system.

- Tab. 1 Darstellung der Erkrankungsschwere der untersuchten Melanom-Patienten anhand der Verteilung der Tumorstadien der American Joint Committee on Cancer (AJCC) und dem TNM-System.

\begin{tabular}{|c|c|c|c|c|c|c|c|}
\hline $\begin{array}{l}\text { AJCC } \\
\text { stage }\end{array}$ & Percentage of patients & T-stage & Percentage of patients & N-stage & Percentage of patients & M-stage & Percentage of patients \\
\hline I & 0 & 1a & 5.3 & 0 & 16.43 & 0 & 48.25 \\
\hline IB & 0 & $1 b$ & 1.52 & $1 \mathrm{a}$ & 19.29 & 1a & 17.48 \\
\hline IIA & 1.38 & $2 a$ & 11.36 & $1 b$ & 7.86 & $1 b$ & 16.08 \\
\hline IIB & 3.45 & $2 b$ & 6.82 & $2 a$ & 8.57 & $1 c$ & 18.18 \\
\hline IIC & 4.83 & 3a & 14.39 & $2 b$ & 5 & & \\
\hline IIIA & 11.72 & $3 b$ & 12.88 & $2 c$ & 9.29 & & \\
\hline IIIB & 11.72 & $4 a$ & 9.09 & 3 & 33.57 & & \\
\hline IIIC & 15.17 & $4 b$ & 38.64 & & & & \\
\hline IV & 51.72 & & & & & & \\
\hline
\end{tabular}

In addition to the MRI evaluation, the demographic data (age and gender), the tumor stage (TNM and AJCC), and the tumor thickness were recorded and analyzed for each patient.

To evaluate whether the shortened MRI protocol for detecting metastases was inferior to the full examination, the TOST test for paired samples with a lower boundary for Cohen's $d-0.3$ and a $90 \%$ confidence interval was performed. Interrater reliabilities were determined by Cohen's kappa. Sensitivities for both protocols were calculated considering the results of this study as well as the results of the clinical reports. Statistical analysis was performed with the software of the jamovi project (jamovi version 1.6; Retrieved from https://www.jamovi.org).

\section{Results}

Of the 150 screened examinations, 147 were included in the study. In three cases the initial clinical diagnosis of a malignant melanoma was revised. Thus, the MRI examinations of these patients were excluded. In all, 68 patients were female and 79 were male with a mean age of 63 years (SD 16.3 years). The mean tumor thickness of the primary melanoma was $4.6 \mathrm{~mm}$ (SD 4.02), whereas the tumor thickness in 17 patients was missing due to unknown primary tumor location. At the time point of the MRI examination, the majority of patients presented with advanced disease: American Joint Committee on Cancer (AJCC) stage IV in 51.7\%, a T-stage 3a or higher in $75 \%$, an $\mathrm{N}$-stage $2 \mathrm{~b}$ or higher in $47.9 \%$, and an M-stage $1 \mathrm{~b}$ or higher in $34.3 \%$ ( $\triangleright$ Table 1 ).

Overall, 73 metastases were detected: 60 were located supratentorially and 13 infratentorially. In 20 (13.6\%) of the examinations, metastases were detected: 2 patients had more than 10 cerebral metastases, 11 patients had 2 to 10 metastases, and 7 patients had a single cerebral metastasis. Table 2 gives an overview of the secondary findings. Importantly, all of the secondary findings were also detected with the shortened MRI protocol ( $\bullet$ Fig. 1).
The mean imaging quality for the FLAIR and for the contrastenhanced T1 MPR was rated with 4, meaning "good imaging quality". The interrater reliability between the two observers using the limited protocol was substantial for the supratentorial location $(\kappa=0.66)$, moderate for the infratentorial location $(\kappa=0.57)$, and substantial independent of location $(\kappa=0.62)$. The interrater reliability between the two observers using the full MRI examination was substantial for the supratentorial location $(\kappa=0.71)$, the infratentorial location $(\mathrm{k}=0.76)$, and independent of location $(\mathrm{K}=0.71)$.

The TOST testing showed that, in general, the shortened MRI protocol was not inferior to the full MRI examination in detecting metastases $(p=0.017)$ and could identify supratentorial $(p=0.026)$ and infratentorial metastases $(p=0.001)$.

Considering all results, the sensitivity for detecting at least one metastasis, if present, was $95 \%$ for the supratentorial location, $100 \%$ for the infratentorial location, and $95 \%$ independent of location for the whole MRI under research conditions. For the restricted MRI protocol, the sensitivity was $90 \%$ for the supratentorial location, $86 \%$ for the infratentorial location, and $85 \%$ independent of location. In the official radiological report, the sensitivity was $84 \%$ for the supratentorial location, $86 \%$ for the infratentorial location, and $85 \%$ independent of location ( $\triangleright$ Table 3 ).

In two cases a single and very small dot-like metastasis was missed with the shortened protocol, compared to the whole protocol under research conditions. In both cases the metastasis was located supratentorially ( $\triangleright$ Fig. 2 ). With the shortened protocol, metastases were missed in three cases in the patient group " 2 to 10 metastases" and in two cases in the group "over 10 metastases". A case of meningeal spread was diagnosed correctly with the shortened protocol ( $\triangleright$ Fig. 3). In contrast, the rater of the shortened protocol correctly detected an infratentorial metastasis in one case that was missed by the raters evaluating the whole examination. In two cases, a single supratentorial metastasis detected in the study was not mentioned in the official report. In 
- Table 2 Overview of the secondary findings in this study. The MRI examination were performed for staging purposes in melanoma patients. All of the findings were also detectable with the ultra-short MRI protocol, containing just two sequences.

- Tab. 2 Überblick über die Nebenbefunde in dieser Studie. Die MRTUntersuchungen wurden zum Staging von Melanom-Patienten durchgeführt. Alle Nebenbefunde waren auch mit dem ultrakurzen MRT-Protokoll aus nur 2 Sequenzen nachweisbar. (DVA = Developmental Venous Anomaly; AVM = arteriovenöse Malformation; $\mathrm{dwm}=$ tiefes Marklager; $\mathrm{NPH}=$ Normaldruckhydrocephalus; $\mathrm{CA}=$ Corpus-Callosum-Winkel).

\begin{tabular}{|l|c|c|}
\hline Secondary findings & $\begin{array}{l}\text { Total number } \\
\text { of cases }(\mathbf{n})\end{array}$ & $\begin{array}{l}\text { Detectable with } \\
\text { shortened protocol (n) }\end{array}$ \\
\hline DVA & 6 & 6 \\
\hline AVM & 1 & 1 \\
\hline Aneurysm & 1 & 1 \\
\hline Meningioma & 3 & 3 \\
\hline $\begin{array}{l}\text { Low grade glioma } \\
\text { (suspected) }\end{array}$ & 1 & 1 \\
\hline Subependymoma & 1 & 1 \\
\hline Vestibular schwannoma & 1 & 1 \\
\hline Old embolic infarction & 6 & 6 \\
\hline $\begin{array}{l}\text { Severe microangiopathy } \\
\text { (dwm Fazekas score } \geq 2)\end{array}$ & 25 & 25 \\
\hline Posttraumatic defect & 1 & 1 \\
\hline NPH (CA < $80^{\circ}$ ) & 2 & 2 \\
\hline $\begin{array}{l}\text { DVA = developmental venous anomaly; AVM = arteriovenous malformation; } \\
\text { dwm = deep white matter; NPH=normal pressure hydrocephalus; CA = cal- } \\
\text { losal angle. }\end{array}$ & \\
\hline
\end{tabular}

the group " 2 to 10 metastases", four metastases detected in the study were not mentioned in the report. In one case, a single supratentorial metastasis that was mentioned in the report was missed by all raters in the study. In three radiological reports with multiple metastases, the exact number of metastases was not mentioned.

Altogether, the scanning time of the regular MRI protocol was 18 minutes and 3 seconds. In detail, axial DWI takes 1 minute and 21 seconds, axial T2 TSE takes 4 minutes and 12 seconds, sagittal FLAIR takes 3 minutes and 2 seconds, native and contrast-enhanced axial T1 TSE each take 2 minutes and 38 seconds, and sagittal contrast-enhanced T1 MPR takes 4 minutes and 12 seconds. In contrast, scanning for the ultra-short MRI protocol with FLAIR and T1 MPR takes 7 minutes and 14 seconds. This represents a time savings of 10 minutes and 49 seconds or $60 \%$. In both protocols, additional time for preparing and positioning of the patient, for planning sequences, and for contrast agent injection must be considered.
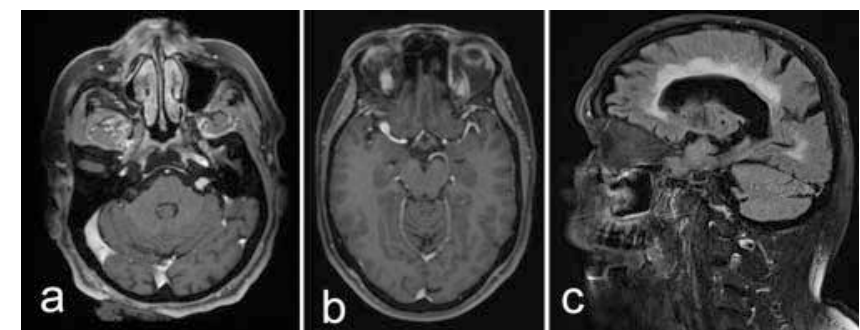

- Fig. 1 Examples of secondary findings in cerebral MRI for staging of melanoma patients. All secondary findings were also detectable with the ultra-short MRI protocol containing just a sagittal Flair and a contrast-enhanced T1 MPR. a Axial reformatted contrast-enhanced T1 MPR of a 77-year-old male patient with a vestibular schwannoma on the left. b Axial reformatted contrast-enhanced T1 MPR of a 66-yearold female patient with an aneurysm of the bifurcation of the right medial cerebral artery. c Sagittal Flair of an 82-year-old male patient with severe microangiopathic white matter changes (Fazekas score 3).

- Abb. 1 Beispiele für Nebenbefunde in zerebralen Staging-MRT bei Melanom-Patienten. Alle Nebenbefunde waren auch mit dem ultrakurzen MRT-Protokoll, bestehend aus einer sagittalen Flair und einer kontrastverstärkten T1 MPR, nachweisbar. a Axial rekonstruierte, kontrastverstärkte T1 MPR eines 77-jährigen Patienten mit einem Vestibularisschwannom als Nebenbefund. b Axial rekonstruierte, kontrastverstärkte T1 MPR einer 66-jährigen Patientin mit einem Mediabifurkationsaneurysma rechts als Nebenbefund. c Sagittale Flair eines 82-jährigen Patienten mit ausgeprägter mikroangiopathischer Marklagerschädigung (fazekas score 3).

\section{Discussion}

Our study shows that an ultra-short MRI protocol markedly reduces examination times and that the focused examination is not inferior to the routine MRI protocol in detecting cerebral melanoma metastases. Very few metastases were missed by the raters with the shortened MRI protocol. Nonetheless, it would not have changed the diagnosis or m-stage in the majority of patients because other cerebral metastases were detected. However, in two cases a single dot-like metastasis was missed, which was diagnosed with the full MRI examination. Retrospectively, these metastases were detectable on the contrast-enhanced T1 MPR images, although it was difficult ( $\vee$ Fig. 2). On the other hand, the rater for the shortened protocol correctly detected an infratentorial metastasis that was not detected by the raters evaluating the whole examination. Furthermore, our results show that sensitivity in a research setting is higher than sensitivity in a clinical setting. Reasons for this phenomenon might be the elevated alertness in a study situation and the interruptions in the workflow in daily clinical work, which are not rare. In contrast, evaluating an MRI examination with just two sequences might lead to a more focused assessment of the images in the clinical routine.

Although we did not observe any false-positive results, for example, cavernomas misinterpreted as metastasis, this problem might represent a downside of a shortened MRI protocol. Thus, it is advisable to confirm rare, positive results with an extended MRI examination. Furthermore, this point illustrates that a shortened protocol is not recommendable for patients with neurologic 
- Table 3 Comparison of the number of metastases detected with the short MRI protocol and the long protocol under research conditions divided by locations. The sensitivity for detecting at least one metastasis, if present, was calculated considering the number of metastases detected in this study as well as the results of the clinical report.

- Tab. 3 Vergleich der Anzahl an Metastasen, die mit dem kurzen und mit dem langen MRT-Protokoll detektiert wurden. Die Sensitivität mindestens eine Metastase zu entdecken, wenn vorhanden, wurde unter Berücksichtigung der Studienergebnisse und der klinischen Befunde berechnet.

\begin{tabular}{|c|c|c|c|c|c|}
\hline & \multicolumn{2}{|l|}{ Short protocol } & \multicolumn{2}{|l|}{ Long protocol } & \multirow[t]{2}{*}{ Detected metastasis overall } \\
\hline & Detected metastasis & Sensitivity (\%) & Detected metastasis & Sensitivity (\%) & \\
\hline Supratentorial & 54 & 90 & 59 & 95 & 60 \\
\hline Infratentorial & 11 & 86 & 12 & 100 & 13 \\
\hline Supra- and infratentorial & 65 & 85 & 71 & 95 & 73 \\
\hline
\end{tabular}
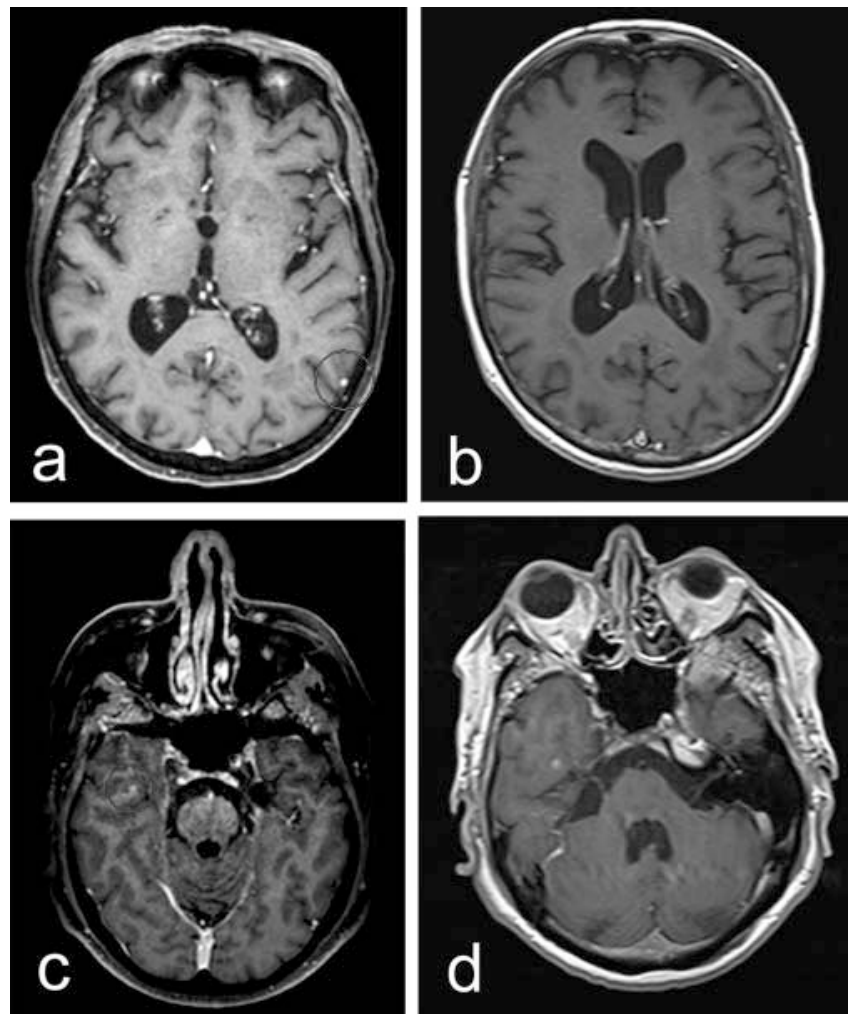

- Fig. 2 These single dot-like metastases were missed by both raters with the shortened MRI protocol and were detected by the raters who evaluated the whole MRI protocol. The left temporoparital metastasis $\mathbf{a}$ and $\mathbf{b}$ and the right temporal metastasis $\mathbf{c}$ and $\mathbf{d}$ are detectable in the axial reformatted contrast-enhanced T1 MPR $\mathbf{a}$ and $\mathbf{c}$ as well as in the axial contrast-enhanced T1 TSE $\mathbf{b}$ and $\mathbf{d}$.

- Abb. 2 Diese singulären, punktförmigen Metastasen wurden von beiden Ratern, die das ultrakurze MRT-Protokoll ausgewertet haben, übersehen, jedoch von den Ratern des Routine-Protokolls entdeckt. Die links temporoparietale Metastase $\mathbf{a}$ und $\mathbf{b}$ sowie die rechts temporale Metastase $\mathbf{c}$ und $\mathbf{d}$ sind jedoch sowohl in der axial rekonstruierten T1 MPR a und $\mathbf{c}$, als auch in der axialen, kontrastverstärkten T1 TSE $\mathbf{b}$ und $\mathbf{d}$ nachweisbar. symptoms or for evaluating known cerebral metastasis at followup examinations.

Expert consensus recommendations for MRI protocols are available in the setting of known cerebral metastasis, for example, for radiation planning [15] or therapy response in studies [16], and for primary cerebral tumors, especially for study situations [17]. However, no general recommendations exist for an MRI screening protocol for neurologically asymptomatic patients with cancer to detect cerebral metastases. As shown in previous studies, contrast-enhanced T1w images are most sensitive for detecting cerebral metastases [18]. Therefore, this sequence represents the centerpiece of each cerebral MRI staging examination and is essential for an ultra-short MRI protocol. As no relevant differences in contrast enhancement in spin echo and gradient echo sequences have been reported [19-21], we chose the MPR for a better spatial resolution. We additionally added the FLAIR sequence to the ultra-short protocol to provide a second contrast, which might be helpful in detecting and differentially categorizing additional findings. In particular, suppressing the cerebrospinal fluid signal increases sensitivity in evaluating the subarachnoid space [22, 23]. Missing relevant incidental findings might be a downside of a restricted protocol. As shown in $>$ Table 2, however, all secondary findings detected using the whole MRI protocol could be detected with the ultra-short protocol as well. Although this was not the goal of this study and not evaluated statistically, we assume that relevant incidental findings will not be missed.

In general, there is a trend to perform shorter and faster MRI examinations [10-13, 24]. In addition to reducing the number of sequences, as performed in this study, faster sequences can be used. Promising attempts include parallel imaging or synthetic MRI $[8,9]$. Alone or taken together, this can lead to relevant reductions in examination times [10]. In this study, the scanning time for the ultra-short MRI protocol was $60 \%$ shorter than for the routine MRI protocol. A combination with accelerated acquisition techniques might further decrease examination times and should be assessed in further studies.

A weak point of the present study is its retrospective design and the relatively high number of examinations without metastases. On the other hand, these are real-life data without previous 

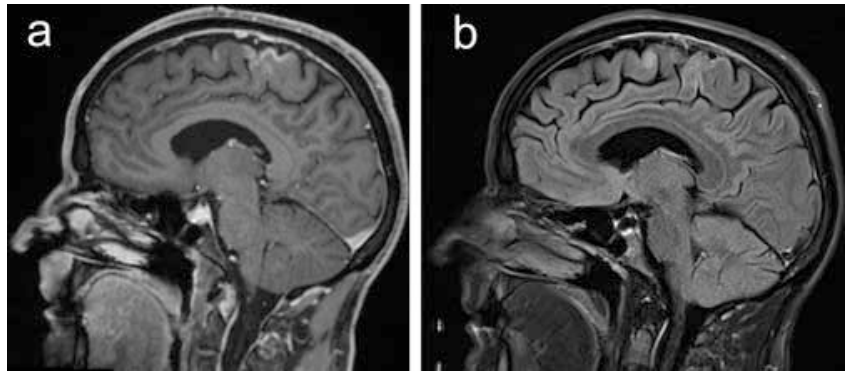

- Fig. 3 A case of meningeal spread, diagnosed correctly with the shortened MRI protocol. Images of a 51-year-old male melanoma patient with AJCC tumor stage IV. The meningeal spread on the right hemisphere is reliably detectable on the sagittal contrast-enhanced T1 MPR images a with a hyperintense correlate in the sagittal Flair images $\mathbf{b}$.

- Abb. 3 Ein Fall mit Meningeosis, der mit dem ultrakurzen MRTProtokoll richtig erkannt wurde. MRT eines 51-jährigen MelanomPatienten im AJCC-Tumorstadium IV. Die rechtshemisphärale Meningeosis ist eindeutig in der sagittalen, kontrastverstärkten T1 MPR abzugrenzen a und hat ein hyperintenses Korrelat in der sagittalen Flair $\mathbf{b}$

selection of cases. Although the majority of neurologically asymptomatic patients have no cerebral metastases [25], the likelihood of developing metastases during the course of the disease is high for certain tumor stages in these patients [26]. Previous studies reported a rate of $12.5 \%$ of cerebral metastases in neurologically asymptomatic melanoma patients [27]. Therefore, the evaluated population with a metastasis rate of $13.6 \%$ is very representative for daily clinical practice, where it is essential to be alert in every case so as not to miss especially small metastases.

The incidence of neoplastic diseases is expected to rise, which will further increase the demands on health care resources [28]. As part of cancer diagnosis, treatment, and follow-up, a rising need for radiologic examinations can be expected, too. Kim et al. reported a reduction in costs by applying a limited MRI protocol for cerebral staging of non-small-cell lung cancer patients [29]. For neurologically asymptomatic melanoma patients, cerebral staging is recommended in later tumor stages, depending on the guidelines for AJCC IIb stages or higher [4, 6]. Indeed, further follow-up MRI examination of the brain for AJCC Ilc and higher stages is recommended every 6 months for at least 3 years by some guidelines [4]. Although a cerebral staging examination in neurologically asymptomatic patients is not necessary in early disease stages, a rising demand for cerebral imaging, especially MRI, can be expected as well. To ensure that high standards are maintained in a system with restricted resources, time- and costefficient examinations are needed. CT scans, which are widely available and fast, are not acceptable as an alternative to cerebral MRI examinations due to the lower sensitivity of CT [7]. Shorter and faster MRI examinations, therefore, might be the key to optimal application and organization of MRI examinations.

\section{Conclusion}

A focused, ultra-short MRI protocol is not inferior to a standard MRI examination in screening for cerebral metastases in neurologically asymptomatic patients. The resulting reduction in examination time might help to more efficiently use our limited MRI capacities and therefore speed up the staging process in tumor patients.

Conflict of Interest

The authors declare that they have no conflict of interest.

References

[1] Pope WB. Brain metastases: neuroimaging. Handb Clin Neurol 2018; 149: $89-112$

[2] Nathoo N, Toms SA, Barnett GH. Metastases to the brain: current management perspectives. Expert Rev Neurother 2004; 4: 633-640

[3] Patel SH, Robbins JR, Gore EM et al. ACR Appropriateness Criteria ${ }^{\circledR}$ follow-up and retreatment of brain metastases. Am J Clin Oncol 2012; 35: 302-306

[4] Leitlinienprogramm Onkologie (Deutsche Krebsgesellschaft, Deutsche Krebshilfe, AWMF): Diagnostik, Therapie und Nachsorge des MLeitlinienprogramm Onkologie (Deutsche Krebsgesellschaft, Deutsche Krebshilfe, AWMF): Diagnostik, Therapie und Nachsorge des Melanoms, Langversion 3.2, 2019, AWMF Registernummer: 032/024OL. http:// www.leitlinienprogramm-onkologie.de/leit-linien/melanomelanoms, Langversion 3.2.

[5] Leitlinienprogramm Onkologie (Deutsche Krebsgesellschaft, Deutsche Krebshilfe, AWMF): Prävention, Diagnostik, Therapie und Nachsorge des Lungenkarzinoms, Lang-version 1.0, 2018, AWMF-Registernummer: 020/007OL. 2018 http://leitlinienprogramm-on-kologie.de/ Lungenkarzinom.98.0.html

[6] Michielin O, van Akkooi AC], Ascierto PA. ESMO Guidelines Committee et al. Electronic address: clinicalguidelines@esmo.org. Cutaneous melanoma: ESMO Clinical Practice Guidelines for diagnosis, treatment and followupt. Ann Oncol Off J Eur Soc Med Oncol 2019; 30: 1884-1901

[7] Schellinger PD, Meinck HM, Thron A. Diagnostic accurancy of MRI compared to CCT in patients with brain metastases. J Neurooncol 1999; 44: $275-281$

[8] Ryu KH, Choi DS, Baek H] et al. Clinical feasibility of 1-min ultrafast brain MRI compared with routine brain MRI using synthetic MRI: a single center pilot study. J Neurol 2019; 266: 431-439

[9] Heidemann RM, Ozsarlak O, Parizel PM et al. A brief review of parallel magnetic resonance imaging. Eur Radiol 2003; 13: 2323-2337

[10] Fagundes ], Longo MG, Huang SY et al. Diagnostic Performance of a 10-Minute Gadolinium-Enhanced Brain MRI Protocol Compared with the Standard Clinical Protocol for Detection of Intracranial Enhancing Lesions. AJNR Am J Neuroradiol 2017; 38: 1689-1694

[11] Greenwood HI. Abbreviated protocol breast MRI: The past, present, and future. Clin Imaging 2019; 53: 169-173

[12] Nael K, Khan R, Choudhary G et al. Six-Minute Magnetic Resonance Imaging Protocol for Evaluation of Acute Ischemic Stroke: Pushing the Boundaries. Stroke 2014; 45: 1985-1991

[13] Chan MV, McDonald SJ, Ong YY et al. HCC screening: assessment of an abbreviated non-contrast MRI protocol. Eur Radiol Exp 2019; 3: 49

[14] Sartoretti T, van Smoorenburg L, Sartoretti E et al. Ultrafast Intracranial Vessel Imaging With Non-Cartesian Spiral 3-Dimensional Time-of-Flight Magnetic Resonance Angiography at 1.5 T: An In Vitro and Clinical Study in Healthy Volunteers. Invest Radiol 2020; 55: 293-303. doi:10.1097| RLI.0000000000000641. PMID: 31895223. 
[15] Lo SS-M, Gore EM, Bradley JD. Expert Panel on Radiation Oncology-Brain Metastases et al. ACR Appropriateness Criteria ${ }^{\circ}$ pre-irradiation evaluation and management of brain metastases. J Palliat Med 2014; 17: 880-886

[16] Kaufmann T], Smits M, Boxerman J et al. Consensus recommendations for a standardized brain tumor imaging protocol for clinical trials in brain metastases (BTIP-BM). Neuro-Oncol 2020; 22: 757-772. doi:10.1093/ neuonc/noaa030. PMID: 32048719; PMCID: PMC7283031

[17] Ellingson BM, Bendszus M, Boxerman J et al. Consensus recommendations for a standardized Brain Tumor Imaging Protocol in clinical trials. Neuro-Oncol 2015; 17: 1188-1198

[18] Deike-Hofmann K, Thünemann D, Breckwoldt MO et al. Sensitivity of different MRI sequences in the early detection of melanoma brain metastases. PloS One 2018; 13: e0193946

[19] Downs RK, Bashir MH, Ng CK et al. Quantitative contrast ratio comparison between T1 (TSE at 1.5T, FLAIR at 3T), magnetization prepared rapid gradient echo and subtraction imaging at 1.5T and 3T. Quant Imaging Med Surg 2013; 3: 141-146

[20] Mirowitz SA. Intracranial lesion enhancement with gadolinium: T1weighted spin-echo versus three-dimensional Fourier transform gradient-echo MR imaging. Radiology 1992; 185: 529-534

[21] Li D, Haacke EM, Tarr RW et al. Magnetic resonance imaging of the brain with gadopentetate dimeglumine-DTPA: comparison of T1-weighted spin-echo and 3D gradient-echo sequences. J Magn Reson Imaging JMRI 1996; 6: 415-424

[22] Ercan N, Gultekin S, Celik H et al. Diagnostic value of contrast-enhanced fluid-attenuated inversion recovery MR imaging of intracranial metastases. AJNR Am J Neuroradiol 2004; 25: 761-765
[23] Vaswani AK, Nizamani WM, Ali M et al. Diagnostic Accuracy of ContrastEnhanced FLAIR Magnetic Resonance Imaging in Diagnosis of Meningitis Correlated with CSF Analysis. ISRN Radiol 2014; 2014: 1-7

[24] Kazmierczak PM, Dührsen M, Forbrig R et al. Ultrafast Brain Magnetic Resonance Imaging in Acute Neurological Emergencies: Diagnostic Accuracy and Impact on Patient Management. Invest Radiol 2020; 55 : 181-189

[25] Fogarty GB, Tartaguia C. The utility of magnetic resonance imaging in the detection of brain metastases in the staging of cutaneous melanoma. Clin Oncol R Coll Radiol G B 2006; 18: 360-362

[26] Barnholtz-Sloan JS, Sloan AE, Davis FG et al. Incidence proportions of brain metastases in patients diagnosed (1973 to 2001) in the Metropolitan Detroit Cancer Surveillance System. J Clin Oncol Off J Am Soc Clin Oncol 2004; 22: 2865-2872

[27] Schlamann M, Loquai C, Goericke S et al. [Cerebral MRI in neurological asymptomatic patients with malignant melanoma]. ROFO Fortschr Geb Rontgenstr Nuklearmed 2008; 180: 143-147

[28] Fitzmaurice C, Allen C, Barber RM. Global Burden of Disease Cancer Collaboration et al. Global, Regional, and National Cancer Incidence, Mortality, Years of Life Lost, Years Lived With Disability, and DisabilityAdjusted Life-years for 32 Cancer Groups, 1990 to 2015: A Systematic Analysis for the Global Burden of Disease Study. JAMA Oncol 2017; 3: 524-548

[29] Kim SY, Kim JS, Park HS et al. Screening of brain metastasis with limited magnetic resonance imaging (MRI): clinical implications of using limited brain MRI during initial staging for non-small cell lung cancer patients. J Korean Med Sci 2005; 20: 121-126 